\title{
Prognosis and Therapeutic Biomarker in the Management of Gastric Adenocarcinoma in Brazzaville
}

\author{
Fidele Mambouene', Dimitry Moudiongui ${ }^{2}$, Fabien Mouamba ${ }^{3}$, \\ Yvon Mabiala ${ }^{4}$, Etienne Mokondjimobe ${ }^{5}$, Donatien Moukassa ${ }^{6}$, \\ Jean Bernard Nkoua Mbon $^{7}$, Ange Antoine Abena ${ }^{8}$ \\ ${ }^{1,2} \mathrm{PhD}$ Student Pending Defense in Service at the Pathological Anatomy Laboratory of the University Hospital \\ of Brazzaville \\ ${ }^{3}$ Pathologist and Assistant at the Faculty of Medicine Pathological Anatomy Laboratory of the University \\ Hospital of Brazzaville \\ ${ }^{4}$ Medical Oncologist of the University Hospital of Brazzaville \\ ${ }^{5}$ Professor of the Doctoral School of Health and Human Biology Faculty of Health Sciences \\ ${ }^{6}$ Anatomopathologist, Professor at the Faculty of Medicine Head of Laboratory Department for Biomedical \\ Research and Analysis Training Faculty of Health Sciences \\ ${ }^{7}$ Professor, Medical Oncologist of the University Hospital of Brazzaville Head of Medical Oncology \\ ${ }^{8}$ Professor, Coordinator of the Doctoral School of Health and Human Biology Faculty of Health Sciences
}

Corresponding Author: Mambouene Fidele

DOI: https://doi.org/10.52403/ijhsr.20220119

\begin{abstract}
Introduction: Gastric cancer is predominantly represented by adenocarcinoma, which is the most common histological type. The latter develops from the gastric epithelium and remains a global public health problem. The aim of the study was to assess the overexpression of the Her2 biomarker of gastric adenocarcinoma in Brazzaville.

Materials and Methods: Samples of gastric carcinomatous tissues (paraffin blocks) were analyzed by the manual immunohistochemistry technique for the evaluation of the Her2 biomarker. Samples were collected retrospectively between January 2008 and December 2018.

Results: during this period, 52 samples were analyzed. The immunohistochemistry results show that the Her2 protein positivity rate in adenocarcinoma cases was $9.6 \%$.

Conclusion: The results obtained during this preliminary study confirm the presence of the Her2 biomarker in $9.6 \%$ of gastric adenocarcinoma cases, which is consistent with the data in the literature.
\end{abstract}

Keywords: Her2, Gastric adenocarcinoma, Immunohistochemistry

\section{INTRODUCTION}

Gastric cancer is mainly represented by adenocarcinoma, which is the most common histological type (Bouvier AM et al; 2004). The latter develops from the gastric epithelium and remains a global public health problem (Bouvier AM et al; 2004). This pathology presents variable prevalence and a poor prognosis. Globally, over one million patients were diagnosed in 2018 (F. Bray et al 2018) and over 780,000 cases of death and two-thirds in low-income countries (Klingelhöfer D et al 2020). Western Europe and North America are medium risk regions, and the highest incidence is reported in Japan, followed by China, South America, and Eastern and Southern Europe Africa is a low risk region (Mellouki I et al; 2014). According to the Brazzaville 2018-2019 cancer registry, the gastric cancer incidence rate is 3.6 per 100,000 inhabitants. The incidence of 
gastric cancer has been declining for 50 years in Western countries, however, although their annual incidence has declined markedly, today it is the third leading cause of cancer death worldwide.

The recognition of the carcinogenic role of infection by Helicobacter pylori is the main advance of the last decade, added to this a diet rich in salt and nitrates then poor storage of food in the cold. Prevention of infestation by this germ may be able to decrease the incidence of this cancer. In most cases, gastric adenocarcinoma is diagnosed in patients with advanced stages (Aparicio $\mathrm{T}$ et al 2004). Research shows on the one hand that gastric adenocarcinoma, in some cases overexpresses Her2, which is a transmembrane receptor involved in the regulation of cell proliferation. The overexpression of Her2 was initially studied in breast cancer. Testing for Her2 status is now mandatory in patients with gastric adenocarcinoma.

Several studies showing the association of gastric adenocarcinoma and Her2 overexpression correlated with prognostic and therapeutic implications via targeted therapies have been carried out worldwide (M TOUATI et al; 2011)

This is how we set out to study the overexpression of Her2 in gastric adenocarcinoma in Congo Brazzaville, which is considered to be an essential biomarker in the management of gastric adenocarcinoma.

The objective of our study is to evaluate the overexpression of the Her2 biomarker in gastric adenocarcinoma and to determine its correlation with the histoepidemiological parameters.

\section{MATERIAL AND METHODS}

We conducted a descriptive study to collect retrospective data made from samples of gastric adenocarcinoma tissue included in paraffin in the period from January 2008 to December 2018 at the Laboratory of Anatomy Pathology (LAP) of the University Hospital of Brazzaville (CHU-B). The inclusion criteria were all epithelial cancers diagnosed meeting the international recommendations of the American Society of Clinical Oncology (ASCO) and the American College of Pathologists (CAP). All non-epithelial gastric cancers, poorly fixed, over-fixed or insufficient samples were excluded.

The search for Bio marker Her2 was carried out by immunohistochemistry according to the following method:

Paraffin blocks diagnosed with gastric adenocarcinoma meeting the international recommendations of the American Society of Clinical Oncology (ASCO) and the American College of Pathologists (CAP) were all chosen for the manual immunostaining technique. Immunohistochemical procedures examining Her-2 expression were performed manually.

The technology used: Ultra vision quanto system using Horseradish Peroxidase (HRP) and Diaminobenzidine (DAB). The following standard practices were performed: To analyze the expression of Her-2 with super Frost plus slides, each was dewaxed in xylene, rehydrated in alcohol baths at decreasing degrees $\left(100^{\circ}, 95^{\circ}\right.$, $70^{\circ}$ ) and boiled for 45 minutes (in a water bath set at $\left.96^{\circ}\right)$ in $10 \mathrm{mM}$ citrate buffer $(\mathrm{pH}$ 6.0) for the restoration of the antigenic sites. Then the slides were incubated for 30 minutes at $37^{\circ} \mathrm{C}$ with primary monoclonal antibodies. Thermo Scientifique's manual Ultra vision detection system uses an indirect biotin-avidin system with a universal biotinylated immunoglobulin secondary antibody. The slides were incubated for 5 minutes with 3,3'diaminobenzidine (DAB) until an appropriate brown color. Then the slides were counterstained with hematoxylin before mounting. Her2 immunostaining was scored using the following scoring system adopted by Hofmann in the ToGA clinical trial: score 0 , no membrane staining or $<10 \%$ of stained cells; $1+$, barely noticeable weak membrane reactivity in $10 \%$ or more of cells or reactivity in only part of cell membrane; $2+$, weak to moderate complete 
or basolateral membrane reactivity in $10 \%$ or more tumor cells; and 3+, strong complete or basolateral membrane reactivity in $10 \%$ or more tumor cells [reference]. Scores of 0 and $1+$ were considered negative for Her2 oncoprotein overexpression, and scores of $3+$ were considered positive. Scores of $2+$ were considered equivocal overexpression, requiring confirmation of $\mathrm{Her} 2$ amplification by the In Situ Fluorescence Hybridization (FISH) technique.

Due to lack of resources, we did not use the in-situ hybridization technique; however, the immunohistochemistry technique is sufficient to determine the Her2 status of tumors in approximately $90 \%$ of cases.

The correlation between Her2 and the histoepidemiological parameters was determined by graphpad software using
Fischer's test as a statistical test, the test was considered significant when $\mathrm{p}$ (degree of significance) was less than 0.05 .

\section{RESULTS AND DISCUSSION RESULTS}

Out of the 52 cases of gastric adenocarcinoma collected were eligible for the realization of Her2. The results were as follows: the ages of our patients ranged from 23 to 86 years old. A male predominance is observed with 34 men and 18 women, i.e. a sex ratio of 1.9. Testing for Her2 status revealed an overexpression rate of $9.6 \%$. In our series 26 cases $(50 \%)$ were score 0,20 cases $(38.4 \%)$ score $1+, 1$ case $(2 \%)$ score $2+$ and 5 cases $(9.6 \%)$ score $3+$ (figure 1). The expression of the Her2 protein in gastric tumors by age group, sex and histological type is shown in Table 1, Table 2 and Table 3, respectively.

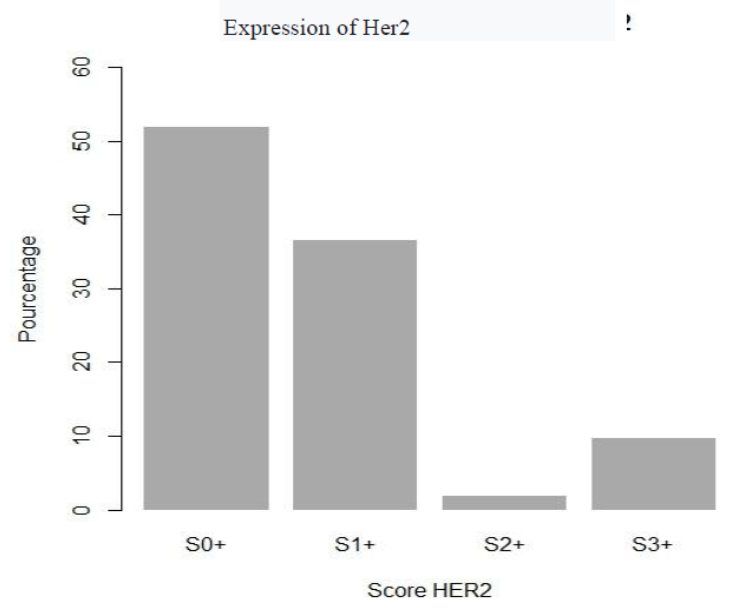

Figure1: expression of Her2

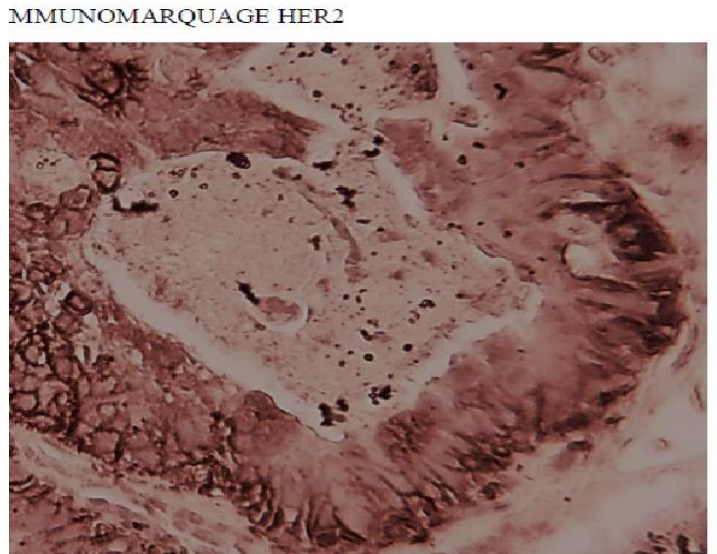

Figure 2: immunolabeling of the Her2 3+ protein in gastric cancer: intense membrane, complete or basolateral in U X20 magnification
There is a male predominance with a sex ratio $\mathrm{M} / \mathrm{F}$ of 1.9 . (34 men and 18 women)

\section{Her2 overexpression and age}

Table I: Distribution of Her2 scores according to age groups

\begin{tabular}{|l|l|l|l|}
\hline & Score 0 et 1 & Score 2 & Score 3 \\
\hline$<50$ & $21(45,6 \%)$ & $0(0 \%)$ & $0(0 \%)$ \\
\hline$\geq 50$ & $25(54,4 \%)$ & $1(100 \%)$ & $5(100 \%)$ \\
\hline Total & 46 & 1 & 5 \\
\hline
\end{tabular}

\section{Overexpression Her2 and Sex}

Table II: Distribution of Her2 scores according to sex

\begin{tabular}{|l|l|l|l|}
\hline & Score 0 et 1 & Score 2 & Score 3 \\
\hline Man & $30(65,2 \%)$ & $1(100 \%)$ & $3(60 \%)$ \\
\hline Woman & $16(34,8 \%)$ & $0(0 \%)$ & $2(40 \%)$ \\
\hline Total & 46 & 1 & 5 \\
\hline
\end{tabular}




\section{Her2 overexpression and histological type}

Table III: distribution of the different scores according to histological types

\begin{tabular}{|l|l|l|l|}
\hline Cells independent & Score 0 et 1 & Score 2 & Score 3 \\
\hline Yes & $17(36,9 \%)$ & $0(0 \%)$ & $1(20 \%)$ \\
\hline No & $29(63,1 \%)$ & $1(100 \%)$ & $4(80 \%)$ \\
\hline & 46 & 1 & 5 \\
\hline
\end{tabular}

\section{Her 2 correlation with}

\section{histoepidemiological parameters}

Table IV: Her2 correlation with histoepidemiological parameters

\begin{tabular}{|l|l|l|l|l|}
\hline Characteristics & $\begin{array}{l}\text { score 0 et } \\
\mathbf{1 +}\end{array}$ & $\begin{array}{l}\text { score } \\
\mathbf{2 +}\end{array}$ & $\begin{array}{l}\text { score } \\
\mathbf{3 +}\end{array}$ & $\begin{array}{l}\mathbf{p}- \\
\text { value }\end{array}$ \\
\hline Sex & 30 & 1 & 3 & $\mathbf{0 . 0 6}$ \\
\hline Man & 16 & 0 & 2 & \\
\hline Women & 21 & 0 & 0 & $\mathbf{0 . 2 6}$ \\
\hline Age & 25 & 1 & 5 & \\
\hline$<50$ & \multicolumn{5}{|l|}{} \\
\hline$>50$ & 1 & 4 & \\
\hline Histological type \\
\hline Tubular ADK & 24 & 0 & 1 & $\mathbf{0 . 0 5}$ \\
\hline cells ind ADK & 17 & 0 & 0 & \\
\hline Pap ADK & 4 & 0 & 0 & \\
\hline Muc ADK & 1 & 1 & \\
\hline
\end{tabular}

\section{DISCUSSION}

The objective of our study was to evaluate the Her2 bio marker in gastric adenocarcinoma in Congo Brazzaville. The methodology adopted consisted in testing for the overexpression of Her2 using the technique of manual immunohistochia. The results obtained will allow health decisionmakers to improve the management of gastric adenocarcinoma, which ranks sixth among cancers in men in Congo Brazzaville, according to the Brazzaville cancer registry for 2018-2019.The evaluation of the overexpression of the Her2 protein was done by the technique of manual immunohistochemistry. As part of the prognostic and therapeutic management of gastric adenocarcinoma, testing for the Her2 protein is very essential. The therapy targeted by trastuzumab, which is an anti Her2, brings a marked and remarkable improvement in the management of gastric adenocarcinoma

In our study, the positivity rate of the immunohistochemical test for the Her2 protein was $9.6 \%$ and this is closely related with our research hypothesis which consisted of evaluating the overexpression of the Her2 biomarker.
Our results are of good quality and valid because previous studies have shown a rate that is similar to our results (Bouche $\mathrm{O}$, 2010). Our results are also in line with those of Abiba et al carried out at the LAP of the Habib Bourguiba University Hospital in Tunisia, who observed a rate of overexpression of the Her2 oncoprotein of $10 \%$ in gastric adenocarcinoma (N. Abida, 2011). On the other hand, the study by Yonerura et al showed a rate of $11.2 \%$ (Yonemura Y, 1991), in agreement with the work of Usheno (Uchino S, 1991) and Garcia et al (Garcia I, 2003). However the results found by Cherbi et al in Algeria are at odds with ours because they showed a lower rate. Indeed, they observed a positivity rate of the Her2 oncoprotein of $7 \%$ with a score of $3+$ (FZ CHERBI, 2016). Other studies have shown lower rates, such as a recent study including two German and English cohorts and the series by Grasch et al which found a positivity value of Her2 of 4\% (Grabsch H, 2010), Hinde el fatemi et al in 2012 in Fez in Morocco also found very discordant results with a positivity rate of $35.5 \%$ with a score of $3+(\mathrm{H}$ El Fatemi, 2012), this rate is much higher than the rate obtained in our study. Never mind, our results obtained are in perfect relation to the hypothesis of our work. Several studies have looked at the expression of Her2 and its correlation with parameters concerning age, sex, histological type, and localization. In our study, we noted a trend of increased Her2 overexpression with age. $100 \%$ who expressed Her 2 were over 50 years of age. This is what is reported by a study by Fei Zhou and Li Ning in China (Zhou F and al, 2012) Contrary to our study, LAHZAOUI TOURIA in Morocco noted a tendency for Her2 decrease with age. $66.7 \%$ who expressed Her2 were under 50 and $64 \%$ who did not express it were over 50 . The average age of those who expressed is 50.66 years and those who did not 56.08 years old.

The correlation between age and Her2 overexpression was not significant in our study ( $p$-value: 0.26), this is what is 
described in the TANNER.M series (Tanner M et al, 2005)

No correlation was noted between sex and Her2 overexpression (p-value: 0.06), this is also evident in TANNER's study. M. (Tanner M et al, 2005).

In our work, we subdivided our samples into two groups: a group which presents a little differentiated ADK with independent cells and a second group which includes the other histological forms according to the WHO 2010 classification to approximate the data in the literature. Thus, it has been observed, as in several studies that the overexpression of Her2 varies according to the histological type, Cravalos $\mathrm{C}$ and A Jimemo have shown that it is less frequent in tumors with independent cells compared to the intestinal form (7\% vs 16 $\%, \mathrm{p}=0.276$ ) (Lordik F and al, 2007)

Lordick et al in their abstract presented to the European Cancer Organization in 2007 concluded that Her2 positivity was significantly different between cell-independent tumors and intestinal forms. (6\% vs $30 \%$ )

This difference is also noted by our study, the TOGA study and other series of literature (Cravalos C and al, 2007; Grabsch $\mathrm{H}$ and al, 2010)

Some studies find discordant results, in particular a series of ZHANG XL published in 2009, the expression of Her2 is more frequent in cancers with independent cells $(26.7 \%$ vs $7.1 \%, \mathrm{p}=0.05$ ) (Zhang XL and al, 2009)

No correlation was demonstrated between the histoepidemiologic parameters and the overexpression of the oncoprotein Her2.

These results are in perfect harmony with the work of LAHZAOUI TOURIA and Kcollaborateurs in Morocco.

In view of the above, our interest is to improve the management of gastric adenocarcinoma via these prognostic and therapeutic biomarkers including Her2.

Regarding the therapeutic benefit, the TOGA study evaluated herceptin associated with chemotherapy based on
CISPLATIN AND 5FU versus chemotherapy alone in the treatment of gastric cancer or locally advanced or metastatic JOG. The main objective was the survival.

The results of this trial showed that the addition of HERCEPTIN to chemotherapy significantly improved the median survival (11.1 months VS 16 months) without notable side effects. The risk of death was reduced by $26 \%$ (BANG YJ and al, 2010)

Since the target of HERCEPTIN is the Her2 protein, testing for its overexpression in gastric adenocarcinoma becomes mandatory

Regarding prognostic benefit, studies investigating the relationship between gastric cancer prognosis and Her2 overexpression have all shown its association with poor prognosis and decreased overall survival. " in 2010 by M. Bayrak the overall survival in patients with $3+$ is much lower than those with a score $2+$ and less (0 and 1+) (Bayrak M and al, 2013)

Another study published by $\mathrm{T}$ Mizutani and $M$ onda suggested that patients with early stage disease who overexpress Her2 had a more unfavorable survival rate than patients who do not express it, but not at the advanced stage ( $\mathrm{T}$ Mizutani and al, 1993)

\section{CONCLUSION}

Improving the management of gastric adenocarcinoma can only be conceived by mastering its prognostic and therapeutic biomarkers. During our study we determined the overexpression of Biomarker Her2 by the manual immunohistochemical technique.

Our objective of evaluating the overexpression of the Her2 bio marker by immunohistochemistry. Thus $9.6 \%$ overexpression of Her2 in gastric adenocarcinoma was obtained. In view of our results, all the authors working on gastric adenocarcinoma and the Her2 protein, found overexpression, although at varying frequencies, which means that 
gastric adenocarcinoma in Congo Brazzaville overexpresses Her2. A largescale study with automated immunohistochemistry techniques, even including in situ hybridization, would be desirable in the future. We would have liked to use an automated immunohistochemical method to verify the expression of Her2 and then do the FISH for equivocal cases, however due to lack of means this was not possible. Subsequent studies with large sampling using more modern techniques such as in situ hybridization and sequencing will make it possible to search for mutations, amplifications, hypermethylations, and to establish the phylogenetic tree. All this will help to improve the management of gastric adenocarcinoma in the Congo Brazzaville

\section{Acknowledgement: None}

\section{Conflict of Interest: None}

\section{Source of Funding: None}

\section{Ethical Approval: Approved}

\section{REFERENCES}

1. Bouvier AM, Remontet L,Jougla E, et al. Incidence of gastrointestinal cancer in France. Gastroenterol clin Biol 2004; $28: 877-81$

2. F. Bray, J. Ferlay, I. Soerjomataram, RL Siegel, LA Torre and A. Jemal, "Global Cancer Statistics 2018: GLOBOCAN Estimates of Global Incidence and Mortality for 36 Cancers in 185 Countries", CA : a Cancer Journal for Clinicians, vol. 68, no. 6, pp. 394-424, 2018.

3. Klingelhöfer D, Braun M, Schöffe N, Brüggmann D, Groneberg DA. Gastric cancer: bibliometric analysis of epidemiological, geographical and socioeconomic parameters of the global research landscape. Int $J$ Health Policy Manag. 2020;x(x):x-X.

4. Mellouki I, Laazar N, Benyachou B, Aqodad N, Ibrahimi A. Epidemiology of gastric cancer: experience of a Moroccan hospital. Pan Afr Med J. 2014 Jan 22;17:42.

5. Abrahao-Machado LF, ScapulatempoNeto C. HER2 testing in gastric cancer: An update. World J Gastroenterol. 2016;22(19):4619-4625. doi:10.3748/wjg.v22.i19.4619

6. Bouche O, Penault- Liorca F. HER2 and gastric cancer: a novel therapeutic target for transtuzumab. Bull Cancer 2010; 97:1429-1440.

7. N.Abid a, A.Khabir a, .Khanfirb, M.Frikha., I; Beyrouti c, T. Boudawaraa. Interest of the study of the overexpression of Her2 in gastric adenocarcinoma in about 100 cases.

8. Yonemura Y,Ninomiya I,Yamaguchi A,Fushida S,Kimura H,Ohoyama S, et al. Evaluation of immunoreactivity for erbb-2 protein as a marker of poor short term prognosis in gastric cancer. Cancer Res $1991 ; 51 . .1034-8$

9. Uchino S, Tsuda H, Maruyama K, Kinoshita T, Sasako M, Saito T, et al. Evaluation of immunoreactivity for erbB2 protein as a marker of poor short term prognosis in gastric cancer. Cancer Res 1991;51:1042-8

10. Garcia I, Vizoso F, Martin A, Sanz I, Abdel-Lah O, Raigoso P, et al. Clinical significance of the epidermal growth factor receptor and HER2 receptor in resectable gastric cancer. Ann Surg Oncol2003;10:234-41

11. FZ CHERBI, S AIMEUR. Investigation of the overexpression of the protein and the amplification of the Her2 gene in stomach cancer by immunohistochemistry and in situ hybridization (FISH). - 2016 di.univ-blida.dz

12. Grabsch H, Sivakumar S, Gray S, Gabbert HE, Muller W, Her2 expression in gastric cancer rare, heterogenous and of no prognostic value-conclusions from 924 cases of two independent series. Cell Oncol 2010; 32:57-65.

13. H El Fatemi, N Hammas, K Idrissi, N Mellas. Protein overexpression and amplification of the HER2 gene in stomach cancer by immunohistochemistry and in situ hybridization: experience of 
CHU HASSAN II in Fes. Pan Afr Med 2012; $13: 79$

14. Tanner M, M Hollmen, junttilia TT, Kapanen Al, Tommola S,J salo and al. Amplification of Her2 in gastric carcinoma association with Topoisomererase I alpha gene amplification, intestinal type,poor prognosis and sensitivity to transtuzumab. Ann Oncol.2005 Feb;16(2):273-8

15. Bayrak M,Olmez DE,Kurt E,Cubukcu E, $\mathrm{T}$ Evrensel, kanat $\mathrm{O}$. prognostic significance of c-erbB2 overexpression in patient with metastatic gastric cancer. Oncol Clin Trad.2013,Avr,13(4); 307Epub 2012 aout.22
16. T Mizutani,Onda M,A Tokunaga, Yamanaka N, Y Sugisaki. Relationship of c-erbB-2 protein expression and gene amplification to invasion and metastasis in human gastric cancer.cancer.1 octobre1993: 72(7): 2083-8

How to cite this article: Fidele Mambouene, Dimitry Moudiongui, Fabien Mouamba et.al. Prognosis and therapeutic biomarker in the management of gastric adenocarcinoma in Brazzaville. Int J Health Sci Res. 2022; 12(1):130-136. DOI: https://doi.org/10. 52403/ijhsr.20220119 